This is an Author's Accepted Manuscript of an article published in Journal of Library \& Information Services in Distance Learning Volume 6, Issue 2, 2012 (copyright Taylor \& Francis), available online at: http://www.tandfonline.com/ (doi:10.1080/1533290X.2012.684430).

\title{
Program-Integrated Information Literacy Instruction for Online Graduate
}

\section{Students}

\section{Swapna Kumar \& Marilyn Ochoa}

\section{University of Florida, USA}

\begin{abstract}
Academic librarians often provide information literacy suppor for specific courses or topics in the form of research guides, one-shot training sessions, library orientations, or by embedding library content into online courses. Less frequently, they provide continuous program-level support on-campus or online. This paper highlights the value of sustained involvement of librarians at the program level to provide information literacy in an online environment. The description of implementation, research results, and strategies for sustainability will be useful to other online programs engaged in equipping online graduate students with essential information literacy skills to succeed in their academic endeavors.

Keywords: online learning, information literacy, faculty-librarian collaboration, distance learning, library instruction
\end{abstract}

\section{Introduction}

The number of students taking online courses at U.S. institutions of higher education has steadily increased in recent years. From the fall semester of 2008 to that of 2009 , the number of 
This is an Author's Accepted Manuscript of an article published in Journal of Library \& Information Services in Distance Learning Volume 6, Issue 2, 2012 (copyright Taylor \& Francis), available online at: http://www.tandfonline.com/ (doi:10.1080/1533290X.2012.684430).

students who took an online course increased from 4.5 million to 5.6 million. ${ }^{1,2}$ Students taking online courses need different forms of support to succeed at a distance. In addition to welldesigned instruction, technical, administrative, and information literacy support is important for online students in post-secondary institutions. ${ }^{3,4}$ Information literacy instruction can help online students succeed in several aspects of their academic endeavors. The significance of support for online students at the institutional, program, and course level for a quality onlinelearning experience and for fostering connectedness to the institution has been highlighted by the Standards for Distance Learning Library Services of the Association of College and Research Libraries $^{5}$ and by the Distance Education \& Training Council this paper describes the design and implementation of information literacy instruction in an online graduate program, and reports on student perceptions of that instructionat the end of their first year in the program.

\section{Institutional Context}

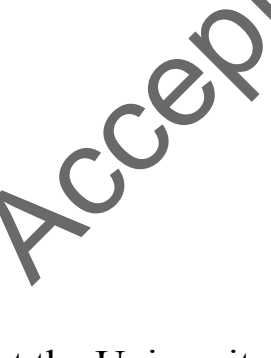

The College of Education at the University of Florida offers several online graduate programs in Education. Assignments in a number of online courses in these programs require students to use online databases, integrate peer-reviewed literature into their writing, and to craft annotated bibliographies. Formal library instruction is not integrated in most courses, although some faculty may provide students with library links, contact a librarian for a session or research guide, or recommend that students consult with a librarian. Incoming students to the online doctoral program in educational technology come from various disciplines such as mathematics, science, art, instructional design, or nursing, and work in diverse environments (e.g. elementary 
This is an Author's Accepted Manuscript of an article published in Journal of Library \& Information Services in Distance Learning Volume 6, Issue 2, 2012 (copyright Taylor \& Francis), available online at: http://www.tandfonline.com/ (doi:10.1080/1533290X.2012.684430).

education, middle or high school, higher education, military), therefore they are not all aware of digital resources and scholarship in the field of educational technology. Notwithstanding their high level of technical skills, students in the online program are all employed full-time, do not live near campus and several have returned to doctoral study after a long hiatus. Students' ability to access, find, evaluate, and synthesize prior research contributes largely to theirsprogress in the doctoral program and their development as scholars and researchers. Instruction and support in accessing library resources would therefore help students complete programactivities successfully and could even reduce frustration and drop-out rates ${ }^{7}$ The importance of support was highlighted during research conducted with the first cohort of the online doctoral program where one-third of students reported that increased libfary instruction was needed for student success in the doctoral program. ${ }^{8}$ The education libarlan and educational technology program coordinator thus collaborated to pilot a program-integrated information literacy project with an aim to (a) provide all students in the online program with information literacy skills and continuous support and (b) create online materials that could be embedded into online courses. Prior research emphasizes the importance of faculty-librarian collaboration in providing online information literacy instruction and of providing such instruction early in an online program. ${ }^{9,10}$ Moreover, the edueation library in the college strives to adhere to Association of College and Research Libraries (ACRL) standards that suggest creating "a program of library user instruction designed to instill independent and effective information literacy skills while specifically meeting the learner-support needs of the distance learning community."

\section{Designing Information Literacy Instruction}


This is an Author's Accepted Manuscript of an article published in Journal of Library \& Information Services in Distance Learning Volume 6, Issue 2, 2012 (copyright Taylor \& Francis), available online at: http://www.tandfonline.com/ (doi:10.1080/1533290X.2012.684430).

In an attempt to design the best possible information literacy instruction for the online program, prior research on the provision of library instruction to online students was reviewed.

In the past, libraries have provided instruction to distant learners by traveling to remote sites, but in the last decade, interactions between academic librarians and students at a distance have become easier with online asynchronous and synchronous technologies. ${ }^{12,13}$ Researchers have reported on the use of online videos and tutorials to successfully explain-literature search processes or the use of specific databases. ${ }^{14,15,16,17}$ Online students candccess such videos and tutorials at their convenience and also view them multiple times. Kimok \& Heller-Ross concluded that it was important to not only provide pre-created standard tutorials in a course, but to also create such tutorials in response to student needs during a course. ${ }^{18}$ In the context of the online doctoral program, it was decided tharessential information literacy topics identified by the education librarian would be addressed in pre-created tutorials. Additionally, online students' needs would be surveyed both at the beginning and during the year to create asynchronous resources that they could use.

Notwithstanding the value of asynchronous resources in online information literacy instruction, Barnhart and Stanfield, ${ }^{19}$ Kontos and $\mathrm{Henkel}^{20}$ and Lietzau and Mann ${ }^{21}$ highlighted the need for synchronous interactions between librarians and online students where librarians can explain procedures in real-time online. Librarians' interactions with online students can be a 'one-shot' session about a specific topic, database, or specific content within a course, or as an embedded librarian within a course or several courses in a college. Such interactions enable students to clarify doubts immediately or follow along as a librarian explains a step-by-step 
This is an Author's Accepted Manuscript of an article published in Journal of Library \& Information Services in Distance Learning Volume 6, Issue 2, 2012 (copyright Taylor \& Francis), available online at: http://www.tandfonline.com/ (doi:10.1080/1533290X.2012.684430).

procedure. Despite the difficulty of coordinating a common time for all online doctoral students to meet, one synchronous session was planned during each semester in the first year of the doctoral program. The librarian and program coordinator decided that skills that could not be "left to chance," would be taught during such sessions, for instance, accessing library resources from off-campus, database searching, and an introduction to bibliographic management software.

While prior research has reported on the value of all these formats and forms of interaction between librarians and online students, course-integrated instruction where students have immediate opportunities to transfer the content of library instruction to course activities has been found to be most effective. 22,23,24,25,26,27,28 Course-integratedinstruction is structured with a specific focus on course assignments and the goal of helping students complete those assignments, combined with information literacystandards and/or a basic set of information literacy skills that have been defined by an accreditation association or a librarian. Programintegrated instruction that would be tafored to the needs of incoming students and help them acquire skills needed to succeed in the online doctoral program was considered crucial in this context. The education librarian and the program coordinator thus decided to develop systematic program-integrated information literacy instruction using asynchronous and synchronous interactions forincoming online doctoral students in 2010. In the long-term, it was hoped that the resources developed could also be useful to students in other programs or in future cohorts.

\section{Implementation}


This is an Author's Accepted Manuscript of an article published in Journal of Library \& Information Services in Distance Learning Volume 6, Issue 2, 2012 (copyright Taylor \& Francis), available online at: http://www.tandfonline.com/ (doi:10.1080/1533290X.2012.684430).

Considering the wide range of skills and backgrounds of incoming online doctoral students in the educational technology program, a needs assessment of students' prior knowledge and skills was conducted before they began the program in summer 2010. In addition to identifying the information literacy skills that students would need in the program, it was important to identify their existing skills and needs in order to design appropriatejinstruction. ${ }^{29,}$ 30,31,32,33 The needs assessment assessed the students' perceived ability to use resources, find appropriate literature, cite and evaluate resources, and their preference of library instruction formats. Library instruction content that encompassed essential information literacy skills and required skills for student success in initial doctoral courses had already been identified. This was adapted based on students' survey responses $(n=21 ; 91 \%)$ about their prior experiences with information literacy instruction, existing skills, and preference for asynchronous tutorials or asynchronous instruction. ${ }^{34}$ Instruction using both synchronous and asynchronous technologies was integrated into the program in the following manner:

Summer 2010. An introductory 1 -hour session was held during the on-campus orientation week at the beginning of the program, which was attended by $100 \%$ of students enrolled at the time $(n=23)$. Topics covered included off-campus access to the library, library services for distance learners including interlibrary loan, and an introduction to catalogs and databases used to locate books or peer-reviewed materials.

Fall 2010. Only half the students rated themselves as experienced or very experienced in using article databases for finding literature in the needs assessment survey. Moreover, students indicated a preference for asynchronous instruction. ${ }^{34}$ Asynchronous learning objects such as QuickTime video tutorials and documents were thus created for step-by-step instruction, placed 
This is an Author's Accepted Manuscript of an article published in Journal of Library \& Information Services in Distance Learning Volume 6, Issue 2, 2012 (copyright Taylor \& Francis), available online at: http://www.tandfonline.com/ (doi:10.1080/1533290X.2012.684430).

in an online repository, and linked within the two courses required for all incoming online doctoral students in the program. Tutorials and videos encompassed access and search topics, specific database use, and citation management as follows: Connecting from Off-Campus; Library Introduction; Searching the Library Catalog; Database Searching; WilsonWeb and EBSCO host; Ulrich Periodicals; ERIC Thesaurus; ISI Web of Knowledge; Dissertation Searches; Citing and Organizing Citations; and Annotated Bibliographies. Sturdents were encouraged to view the learning objects and to use the library help forum that was provided within the courses and monitored by a librarian if they had questions. Thirteen of 22 (59\%) students used the asynchronous learning objects.

Students struggled to identify peer-reviewed scholarship in an initial course activity, therefore the librarian taught a 45-minute synchronous session within the virtual classroom in the online course, and answered students' questions in real-time. Fifteen of 22 (68\%) students attended the synchronous session.

Spring 2011. In a poll at the end of 2010, students reported their lack of experience using bibliographic management tools, a topic identified as important to their success in the doctoral program. The libratian subsequently conducted a synchronous session on RefWorks, a software available at the university, that was attended by 14 of $19(74 \%)$ enrolled students. In one of their required courses, students were also required to complete a group activity on the use of APA style and annotated bibliographies. Furthermore, to reinforce and check that students were familiar with off-campus access and able to access library resources, they were required to provide a screenshot of their connection to the library catalog from off-campus to the course instructor. 
This is an Author's Accepted Manuscript of an article published in Journal of Library \& Information Services in Distance Learning Volume 6, Issue 2, 2012 (copyright Taylor \& Francis), available online at: http://www.tandfonline.com/ (doi:10.1080/1533290X.2012.684430).

Summer 2011. Students had to complete a literature review in the required summer seminar. To reinforce and extend the content of the prior online synchronous session, and to help them with bibliographic management, the librarian taught a one-hour advanced Refworks session oncampus when students attended a one-week summer session. All $18(100 \%)$ attended and were able to ask questions in real-time.

\section{Data Collection and Analysis}

Student perceptions of the information literacy instruction provided in the first year of the online doctoral program (June 2010-June 2011) were assessed using a short anonymous survey in July 2011. The survey included items about (a) sudent satisfaction with different components of library instruction and (b) their perceivedyalue of those components to their learning in the program and for the improvement of their information literacy skills. A 3-point Likert-scale was used (e.g. not satisfied, satisfied, and very satisfied) and an option was included for students who had not attended the instruction or not used a resource ('I did not attend this session/use this resource'). Open-ended questions were included to gather student feedback on how well each component worked and to ask for students' suggestions for improving online information literacy instruction for future students in the program. Twelve of the 18 students $(66.6 \%)$ enrolled in the program at the end of the first year responded to the survey.

\section{Findings}


This is an Author's Accepted Manuscript of an article published in Journal of Library \& Information Services in Distance Learning Volume 6, Issue 2, 2012 (copyright Taylor \& Francis), available online at: http://www.tandfonline.com/ (doi:10.1080/1533290X.2012.684430).

Students' reported satisfaction with the information literacy instruction provided and its perceived value for their completion of assignments during the first year of the online doctoral program is presented in Table 1 . On a scale of 1 to 3 , students were most satisfied with the synchronous online sessions $(M=2.75 \& 2.58)$ and face-to-face sessions $(M=2.67)$ and perceived the online synchronous sessions as most valuable $(M=2.75 \& 2.58)$ for completing assignments in the first year of the online program. The mean student rating for satisfaction with asynchronous learning objects and their value for completing assignments was 2 or less. On a scale of 1 to 3 , the mean student rating for improvement in their ability to access online resources, to search for online resources, to distinguish between peer-reviewed and non-peerreviewed resources, and to manage their research was higher than 2.5 (Table 1). Students' mean rating of the usefulness of instruction in helpingthem to cite appropriately was 2.33 , indicating that more instruction should be provided in this area. 
This is an Author's Accepted Manuscript of an article published in Journal of Library \& Information Services in Distance Learning Volume 6, Issue 2, 2012 (copyright Taylor \& Francis), available online at: http://www.tandfonline.com/ (doi:10.1080/1533290X.2012.684430).

Table 1: Students' satisfaction and perceived value of library instruction in Year 1

Please rate your satisfaction with the library instruction you received for Mean SD conducting research in Year 1 (Not Satisfied, Satisfied, Very Satisfied). $\quad(n=12)$

$\begin{array}{lll}\text { Summer 2010: On-campus library orientation session. } & 2.17 & 0.58\end{array}$

$\begin{array}{lll}\text { Fall 2010: Synchronous session about types of resources } & 2.58 & 0.9\end{array}$

Fall 2010: Asynchronous learning objects (video tutorials, PDF documents) $2.90^{\circ} 1.04$

Spring 2011: Synchronous session about Refworks 2.750 .45

Summer 2011: On-campus session on Refworks 2.670 .49

Please rate the value of the following to your ability to successfinty

complete assignments in Year 1 (Not Valuable, Valuable, Very Valuable).

Summer 2010: On-campus library orientation session $\quad \begin{array}{lll}2.25 & 0.62\end{array}$

Fall 2010: Synchronous session about types of resourdes $\quad 2.58 \quad 0.90$

Fall 2010: Asynchronous learning objects (videotutorials, PDF documents) $\quad 1.83 \quad 0.94$

$\begin{array}{lll}\text { Spring 2011: Synchronous session aboutRgfworks } & 2.75 & 0.45\end{array}$

Summer 2011: On-campus session on Refworks $\quad \begin{array}{lll}2.50 & 0.52\end{array}$

Please rate your agreement with the following (Strongly Disagree, Agree,

Strongly Agree)

The library instruction in Year 1 has improved my ability to access online $\quad \begin{array}{lll}2.67 & 0.49\end{array}$

resources

The library instruction in Year 1 has improved my search abilities

$2.58 \quad 0.51$

The library instruction in Year 1 has increased my confidence in finding $\quad \begin{array}{lll}2.50 & 0.52\end{array}$

resources

$\begin{array}{lll}\text { The library instruction in Year } 1 \text { has helped me distinguish between peer- } & 2.67 & 0.49\end{array}$

reviewed and non-peer-reviewed resources

$\begin{array}{lll}\text { The library instruction in Year } 1 \text { has helped me manage my research } & 2.58 & 0.51\end{array}$

$\begin{array}{lll}\text { The library instruction in Year } 1 \text { has helped me cite appropriately } & 2.33 & 0.65\end{array}$ 
This is an Author's Accepted Manuscript of an article published in Journal of Library \& Information Services in Distance Learning Volume 6, Issue 2, 2012 (copyright Taylor \& Francis), available online at: http://www.tandfonline.com/ (doi:10.1080/1533290X.2012.684430).

When asked to provide feedback on the different components of library instruction in the first year, six of twelve students highlighted the synchronous sessions as valuable, describing them as "well structured and informative," "interactive, we could ask questions" and "valuable because you could refer back to them." One student commented,

I thought it covered everything that I needed to know. The format was easy to follow and flowed well from one topic to the next. I found the sessions to be very helpful, and I feel comfortable using these resources on a dailybasis.

In response to a question about their continued learning beeds, students requested advanced instruction in bibliographic management tools and in citation styles. When asked to provide suggestions for improving library instruction for future students, three students responded that it was "effective as-is." One strydent wrote, "I wouldn't change anything. I think it provided everything I needed to know, and Thave found myself using everything that was discussed so it was all useful." Twolstudents suggested providing students with access to the asynchronous resources before they begin coursework in the program, so that they can prepare for doctoral schools

\section{Discussion and Implications}

This study was conducted with a small sample of online doctoral students in education who were working professionals and may not be representative of the larger population of online graduate students in other disciplines at post-secondary institutions in the United States. Due to 
This is an Author's Accepted Manuscript of an article published in Journal of Library \& Information Services in Distance Learning Volume 6, Issue 2, 2012 (copyright Taylor \& Francis), available online at: http://www.tandfonline.com/ (doi:10.1080/1533290X.2012.684430).

several factors, the number of participating students decreased from 23 to 18 students during the first year of the program. Nevertheless, the implementation of online information literacy instruction and the findings are discussed here with respect to implications for the online doctoral program at our college and for other online programs seeking to include program-integrated information literacy instruction.

In the needs assessment at the beginning of the year, $57 \%$ of incoming students $(n=21)$ reported that they had previously used online tutorials for information literacy instruction, and that they preferred to learn from asynchronous resources (e.g. videocasts, video tutorials, Adobe pdfs) rather than synchronous interactions with a librarian. ${ }^{34}$ The librarian and program coordinator, therefore, focused on the creation of asynchronous resources, but included synchronous interactions based on the research rewed and their instructional experience. In the year-end survey, students reported high satisfaction with the synchronous interactions that they perceived as most useful to their sugcess in program assignments. Possible reasons for students' low rating of asynchronous resources could be that they did not appreciate the importance of reviewing these resources or their relevance to program assignments. It is also possible that they were dissatisfied with the quality of the resources. Fifty-nine percent of students reviewed the asynchronous resources whereas $68 \%$ to $100 \%$ of students attended the synchronous sessions offered during the year. Students were required to attend face-to-face synchronous sessions and were requested to attend online synchronous sessions as much as possible, but they were not required to view the resources provided as part of their course grades or assignments. The program coordinator highlighted the value of the asynchronous resources in 
This is an Author's Accepted Manuscript of an article published in Journal of Library \& Information Services in Distance Learning Volume 6, Issue 2, 2012 (copyright Taylor \& Francis), available online at: http://www.tandfonline.com/ (doi:10.1080/1533290X.2012.684430).

an email but did not require students to view them, which could be a reason for students' low use of resources.

Lessons learned for future implementation of information literacy instruction in our program were (a) not to rely completely on students' professed preference for one format of instruction over the other, but to provide as many forms of interaction with the librarian as possible (b) to stress the importance of students' information literacy skills to their success in the program (c) to require the viewing of asynchronous objects that contained content we had identified as crucial to students' information literacy and success jn the program and (d) to place the asynchronous resources at strategic points before assignments or content in the course. In this instance, technical issues resulted in the placement of all the resources in one folder so that they could be accessed across courses in this online program as well as other programs. It is possible that the placement of asynchronous resourcesint the course might have been a reason for nonuse. Further research in the program will focus on the implementation of these lessons learned and students' use of asynchronous resources or participation in synchronous interactions in information literacy instruction.

Based on these implementation experiences and students' perceptions, we make the following suggestions for others interested in integrating information literacy support in online programs.

- A needs assessment is crucial: Identifying the information literacy skills that students will need to succeed in an online program, combined with an assessment of their existing skills and experiences can help determine the content and format of information literacy instruction in the online program. 
This is an Author's Accepted Manuscript of an article published in Journal of Library \& Information Services in Distance Learning Volume 6, Issue 2, 2012 (copyright Taylor \& Francis), available online at: http://www.tandfonline.com/ (doi:10.1080/1533290X.2012.684430).

- A continuous assessment of program and student needs should follow as students proceed through an online program: After students use pre-created instructional resources, the regular monitoring of students' learning needs and course assignments can contribute to the development of new content and flexible instruction.

- The academic librarian should interact with students in different media and use multiple formats of instruction: While some students appreciate the real-time interaetion with the librarian, not all online students can attend such sessions. Providing archives of synchronous interactions and step-by-step asynchronous resources such as tutorials or pdfs can help students with different learning styles. Theavailability of a help forum and access to a librarian can also be invaluable.

- The placement of asynchronous resources and librarian availability within online courses and programs should be carefully considered: Information literacy instructional resources should be placed at certain points in the program or coursework where students see them as relevant, and students should be required to view or use them. Students might not realize the value of information literacy instruction and might not use the resources unless required to do so. In that context, highlighting the value of information literacy instruction to students' success in an online program will contribute greatly to the use and success of such instruction.

- Faculty-librarian collaboration is essential at every step of the process: Beginning with the identification of program needs and the resources already existing in an academic library, the continuous collaboration between faculty and academic librarians is important to the integration of information literacy instruction at every point in an online program. 
This is an Author's Accepted Manuscript of an article published in Journal of Library \& Information Services in Distance Learning Volume 6, Issue 2, 2012 (copyright Taylor \& Francis), available online at: http://www.tandfonline.com/ (doi:10.1080/1533290X.2012.684430).

Ideally, a collaborative formative evaluation and reflection on what can be improved in the future should accompany this process.

\section{Conclusion}

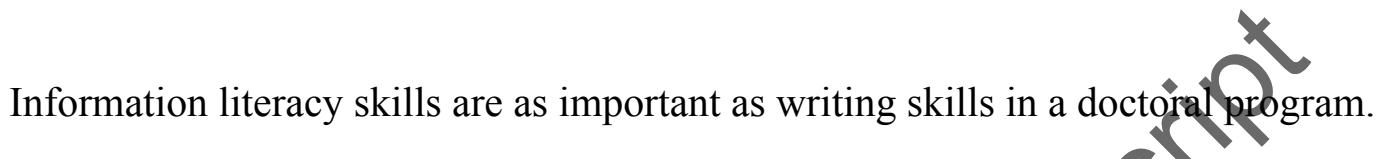

Graduate students who live and work at a distance from the university and might be returning to school after a hiatus cannot be expected to use electronic databases on to evaluate and integrate digital scholarship into their coursework without instruction In this study, instruction was intentionally integrated into the program at regular intervals and in different formats (synchronous or asynchronous), enabling greaterinelvement between the librarian and students. Online students' needs were regularly explored, monitored, and addressed as students progressed through the program. Built on strong librarian-faculty collaboration, a learner needs assessment, the use of different instructional formats, and an evaluation, this library instruction project is a model that can be customized and implemented in other online programs and disciplines to support online students and provide them with skills to succeed in online learning.

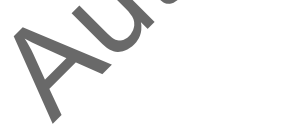

${ }^{1}$ I. Elaine Allen and Jeff Seaman, "Learning on Demand: Online Education in the United States," (Babson Park MA: Babson College Survey Research Group, 2009). Retrieved from www.sloanconsortium.org/publications/survey/pdf/learningondemand.pdf.

${ }^{2}$ I. Elaine Allen and Jeff Seaman, "Class Differences: Online Education in the United 
This is an Author's Accepted Manuscript of an article published in Journal of Library \& Information Services in Distance Learning Volume 6, Issue 2, 2012 (copyright Taylor \& Francis), available online at: http://www.tandfonline.com/ (doi:10.1080/1533290X.2012.684430).

States, 2010," Retrieved from http://sloanconsortium.org/sites/default/files/class differences.pdf.

${ }^{3}$ Maria LaPadula, "A Comprehensive Look at Online Student Support Services for Distance

Learners," American Journal of Distance Education 17, no. 2 (2003): 119-28.

${ }^{4}$ Alan Tait and Roger Mills (Eds.), "Rethinking learner support in distance education:

Change and continuity in an international context," (London: Routledge Falmer, 2003).

5 "Standards for Distance Learning Library Services, " Association of College and Research

Libraries, accessed December 19, 2011,

http://www.ala.org/acrl/standards/guidelinesdistancelearning.

6 "Policies, procedures, standards, and guides of the Accrediting Commission of the Distance

Education and Training Council, Distance Education Training Council," (Washington, DC:

DETC Accrediting Council, 2012).

${ }^{7}$ Cheng-Yuan Lee, "Student Motivation in the Online Learning Environment," Journal of Educational Media \& Library Sciences 37 , no. 4 (June 2000): 367-75.

${ }^{8}$ Swapna Kumar, Kara Dawson,Erik W. Black, Catherine Cavanaugh and Christopher D. Sessums, "Applying the Community of Inquiry framework to an online professional practice doctoral program, ' International Review of Research in Open and Distance Learning 35, no. 6 (2011): 126-142.

${ }^{9}$ Dee Bozeman and Rachel Owens, "Providing Services to Online Students: Embedded Librarians and Access to Resources," Mississippi Libraries 72, no. 3 (Fall 2008): 57-9.

${ }^{10}$ Linda L. Lillard, et al., "Embedded Librarians: MLS Students as Apprentice Librarians in Online Courses," Journal of Library Administration 49, no. 1/2 (January/March 2009): 11-22. 
This is an Author's Accepted Manuscript of an article published in Journal of Library \& Information Services in Distance Learning Volume 6, Issue 2, 2012 (copyright Taylor \& Francis), available online at: http://www.tandfonline.com/ (doi:10.1080/1533290X.2012.684430).

${ }^{11}$ ACRL, "Information Literacy Competency Standards," p. 5.

${ }^{12}$ K. Stuart Ferguson and Alice Ferguson, "The Remote Library and Point-of-Need User

Education: An Australian Academic Library Perspective," Journal of Interlibrary Loan,

Document Delivery \& Information Supply 15, no. 3 (2005): 43-60.

13 Jill S. Markgraf, "Librarian Participation in the Online Classroom," Internet Reference

Services Quarterly 9, no. 1/2 (2004): 5-19.

${ }^{14}$ Wendy Holliday, Sharolyn Ericksen and Britt Fagerheim, "Instruction in a Virtual

Environment: Assessing the Needs for an Online Tutorial," The Reference Librarian (2006):

$187-211$.

${ }^{15}$ Elizabeth Blakesley Lindsay, Lara Cummings and Corey M. Johnson, "If You Build It, Will

They Learn? Assessing Online Information Literacy Tutorials," College \& Research

Libraries 67, no. 5 (September 2006): 429=45.

${ }^{16}$ Rachel G. Viggiano, "Online Tutorials as Instruction for Distance Students," Internet

Reference Services Quarterly 9,10. 1/2 (2004): 37-54.

${ }^{17} \mathrm{Li}$ Zhang, "Effectively Incorporating Instructional Media into Web-based Information

Literacy," The Electronic Library 24, no. 3 (2006): 294-306.

${ }^{18}$ Debra Kimok and Holly Heller-Ross, "Visual Tutorials for Point-of-Need Instruction in Online Courses," Journal of Library Administration 48, no. 3/4 (2008): 527-43.

${ }^{19}$ Anne C. Barnhart and Andrea G. Stanfield, "When coming to campus is not an option: Using web conferencing to deliver library instruction," Reference Services Review, 39, no 1 (2011):

$58-65$. 
This is an Author's Accepted Manuscript of an article published in Journal of Library \& Information Services in Distance Learning Volume 6, Issue 2, 2012 (copyright Taylor \& Francis), available online at: http://www.tandfonline.com/ (doi:10.1080/1533290X.2012.684430).

${ }^{20}$ Fotini Kontos and Harold Henkel, "Live Instruction for Distance Students: Development of Synchronous Online Workshops," Public Services Quarterly 4, no. 1 (2008): 1-14.

${ }^{21}$ Julie Arnold Lietzau and Barbara J. Mann, "Breaking out of the Asynchronous Box: Using Web Conferencing in Distance Learning," Journal of Library \& Information Services In Distance Learning 3, no. 3-4 (2009): 108-19.

22 Barbara Kay Adams, "Library lecture seminars and workshops in course integrated instruction," The Southeastern Librarian, 38 (1988): 144-146.

${ }^{23}$ Francesca Allegri, "Course integrated Instruction: Metamorphosis for the twenty-first century," Medical Reference Services Quarterly 4 (Winter1985): 47-66.

${ }^{24}$ William Badke, "Ramping Up the One-Shot," Online(Weston, Conn.) 33, no. 2 (March/April 2009): 47-9.

${ }^{25}$ Penny M. Beile, "Effectiveness of Course-Integrated and Repeated Library Instruction on Library Skills of Education Students "Journal of Educational Media \& Library Sciences 40, no.

3 (March 2003): 271-7.

${ }^{26}$ Karen Bordonaro and Gillian Richardson, "Scaffolding and Reflection in Course-Integrated Library Instruction," The Journal of Academic Librarianship 30, no. 5 (September 2004): 391401.

${ }^{27}$ Russ A. Hall, "The "embedded" librarian in a freshman speech class," College \& Research Libraries News, 69, no 1 (2008): 28-30. 
This is an Author's Accepted Manuscript of an article published in Journal of Library \& Information Services in Distance Learning Volume 6, Issue 2, 2012 (copyright Taylor \& Francis), available online at: http://www.tandfonline.com/ (doi:10.1080/1533290X.2012.684430).

${ }^{28}$ Linda Lawrence Stein and Jane M. Lamb, "Not just another BI: Faculty-Librarian

Collaboration to guide students through the research process," Research Strategies 16, no. 1

(1998): 29-39.

${ }^{29}$ Nancy H. Dewald, Ann Scholz-Crane and Austin Booth, "Information literacy at a distance: instructional design issues," The Journal of Academic Librarianship 26, no. 1 (January 2000): $33-44$.

${ }^{30}$ Colin Higgins, "Applying Instructional Design theory in academic libraries," Library \& Information Update (July 2010): 22.

${ }^{31}$ Indira Koneru, "ADDIE: Designing Web-enabled Information Literacy Instructional Modules," DESIDOC Journal of Library \& Information Fechnology 30, no. 3 (May 2010): 2333.

32 Alexius Smith Macklin, "Theory into Practice: Applying David Jonassen's Work in Instructional Design to Instruction Programs in Academic Libraries," College \& Research Libraries 64, no. 6 (November2003): 494-500.

33 Jerilyn Veldof, "Take a ride on the design cycle: Instructional design for librarians. In Integrating information literacy into the college experience," (Pierian Press, 2003): 175-181.

${ }^{34}$ Swapna Kumar, Marilyn N. Ochoa and Mary E. Edwards, "Considering Information Literacy Skills and Needs: Designing Library Instruction for the Online Learner," Communications and Information Literacy 6, no. 1 (In Press). 